\section{Incorporating Eye Tracking Technology and Conjoint Analysis to Better Understand the Green Industry Consumer}

\author{
Bridget K. Behe ${ }^{1}$ \\ Department of Horticulture, Michigan State University, East Lansing, MI \\ 48824
}

\author{
Benjamin L. Campbell, ${ }^{1,2}$ \\ Department of Agricultural and Resource Economics, University of \\ Connecticut, 1376 Storrs Road Unit 4021, Storrs, CT 06269
}

Hayk Khachatryan

Food and Resource Economics Department and Mid-Florida Research and Education Center, University of Florida, Apopka, FL 32703

Charles R. Hall

Department of Horticultural Sciences, Texas A\&M University, College Station, TX 77843

Jennifer H. Dennis

Departments of Horticulture and Landscape Architecture and Agricultural Economics, Purdue University, West Lafayette, IN 47907

Patricia T. Huddleston

Department of Advertising and Public Relations, Michigan State University, East Lansing, MI 48824

\section{R. Thomas Fernandez Department of Horticulture, Michigan State University, East Lansing, MI 48824}

Additional index words. visual behavior, choice analysis, multinomial logit, segmentation analysis

\begin{abstract}
Plants are often merchandised with minimal packaging; thus, consumers have only the plant (intrinsic cue) or information signs (extrinsic cues) on which to assess the product and base their purchase decision. Our objective was to segment consumers based on their preferences for certain plant display attributes and compare their gaze behavior when viewing plant displays. Using conjoint analysis, we identified three distinct consumer segments: plant-oriented $(73 \%)$, production method-oriented $(11 \%)$, and price-oriented $(\mathbf{1 6 \%})$ consumers. Using eye tracking technology, we show that subjects spent more visual attention to cues in the horticultural retail displays that were relatively more important to them. For example, plant-oriented consumers were the fastest segment to fixate on the plants and looked at the plants for longer amounts of time compared with the other segments. Production method-oriented consumers looked at the labeling related to production method for a longer duration, whereas the price-oriented consumer looked at the price sign the longest. Findings suggest that retailers should carefully consider the type of information included on retail signage and the visual impact it has on different consumers.
\end{abstract}

Received for publication 29 May 2014. Accepted for publication 29 Sept. 2014

State funds for this project were matched with federal funds under the Federal-State Marketing Improvement Program of the Agricultural Marketing Service, U.S. Department of Agriculture.

We thank Vineland Research and Innovation Centre (Vineland Station, Ontario, Canada) for their contributions to this project. Technical assistance by Lynne Sage was invaluable to completing this study.

${ }^{1}$ Senior authorship shared equally by Behe and Campbell.

${ }^{2}$ To whom reprint requests should be addressed; e-mail ben.campbell@uconn.edu. before using them in judgments. Decades of consumer research has documented the persistent impact that price has on product perceptions (Dodds et al., 1991; Gabor and Granger, 1961; Janakiraman et al., 2006; Rao, 2005; Vanhuele et al., 2006). Other extrinsic cues such as brand (Allison and Uhl, 1964; Richardson et al., 1994) and packaging (Koutsimanis et al., 2012; McDaniel and Baker, 1977) are often also assessed when consumers make product choices.

With respect to plant purchasing, plant quality is nearly always identified as an important purchase factor to consumers (Behe and Barton, 2000; Hudson et al., 1997; Klingeman et al., 2004). Because plants are sold with very little packaging and often do not have brand names, consumers mainly use intrinsic cues (the plant themselves) and extrinsic cues (tags or signs when available) in the purchase decision. Understanding the consumer segment that uses each type of cue can help retailers improve the shopping process, which may lead to greater customer satisfaction and improved sales.

To better understand the role of intrinsic and extrinsic cues, researchers have typically relied on various techniques such as focus groups and experiments. As technology has evolved, researchers have explored the use of new techniques to examine drivers of purchase. Recently developed technologies such as eye tracking technology (ETT) allow researchers to see exactly what the consumer sees, thereby allowing for a better understanding of the consumer mind set. Given its recent adoption, the literature using ETT on retail plant displays is sparse. To fill this void and examine the potential impact on the green industry, we used ETT to investigate what captures attention in horticultural retail displays to better understand cue use. Our objective was to investigate the use of intrinsic cues (plants) and extrinsic cues (signs) in retail plant displays with ETT. Using visual behavior data within conjoint analysis framework, we gain a better understanding of how consumers view cues during the purchase decision.

An important contribution of this study to both methodological and applied research is the unique combination of visual behavior and stated preference data within the choice analysis framework. The first componentconjoint analysis - has routinely been used to understand the effects of product attributes and demographic characteristics on choice decisions. Conjoint studies have been used as a means to elicit consumer preferences for a wide range of ornamental products such as Christmas trees (Behe et al., 2005b), landscapes (Behe et al., 2005a; Zagaden et al., 2008), plant containers (Hall et al., 2010), and mixed flowering annual containers (Mason et al., 2008). Hall et al. (2010) found that $13 \%$ of plant preference survey participants valued an extrinsic cue, carbon footprint label, more than other product cues such as price, plant container type, and waste composition in the container. Building on that study, Behe et al. (2013b) used a conjoint design to identify nine consumer segments, 
focusing on their gardening purchases, and documented differences in consumer preferences for plant provenance and environmental attributes of transplants.

Although techniques such as conjoint analysis are invaluable to understanding the consumer mind set, most cases use stated preference data, which has been subject to criticism for systematic biases (e.g., hypothetical commitment bias) (Carson and Louviere, 2011). Hence, the second component of our framework-ETT - can be applied in conjunction with commonly used experimental techniques (e.g., conjoint analysis) to mitigate these biases and gain an in-depth understanding of behavioral mechanisms underlying consumers' choice decisions. Wedel and Pieters (2008) reported that, "The areas in the visual brain are highly specialized to process information collected during eye fixations and continuously interact with areas that direct eye movement to salient and/or informative locations in visual scenes and stimuli, which enables purposeful and goal-directed eye movement" (p. 13-14). In other words, people do not look randomly and the subconscious movement of the eye is guided by the type of information sought and its value to the task at hand. The bulk of the peer-reviewed studies using ETT investigated the process of reading by following eye movements (see Rayner, 1998, for a 20-year review of this subject).

Visual behavior data were previously used to investigate whether branded products receive more visual attention compared with unbranded products regardless of product size (Teixeira et al., 2010). Meissner and Decker (2010) demonstrated that consumers spent more time (fixations) viewing product attributes that were more important to them. Kuisma et al. (2010) found that animation in online advertisements drew the viewer's attention more for vertical advertisements compared with horizontal advertisements. Patalano et al. (2009) documented that consumer indecisiveness was positively related to time spent viewing information about the purchase as well as time spent looking away from information directly related to that choice task. ETT methods have also been used to examine the effects of package label design on individual choice decision-making behavior. For example, Bix et al. (2009) investigated the prominence of package warnings on over-the-counter medicines and found that they were not readily viewed by consumers. Sorensen et al. (2012) showed that a product name on a label attracted six times more attention than any organic production claim, whereas illustrations captured more attention than health claims, even if the illustration was irrelevant. Behe et al. (2013a) recently demonstrated the potential use of ETT for analyzing green industry consumer behavior.

\section{Methodology}

Participants. Subjects were recruited to the study by various means (Craig's List, local newspaper advertisements, and flyers posted proximate to the study locations) in six North American universities or research centers, including Apopka, FL; College Station, TX; West Lafayette, IN; East Lansing, MI; St. Paul, MN; and Vineland Station, Ontario, Canada. These locations were chosen given their geographic distance to the participating institutions, but also given their dispersion throughout the United States and Canada. The number of panelists per location ranged from 48 to 67 . The total number of individuals who agreed to participate in the study was 330 .

Experiment design and procedures. During the Summer 2012, the 330 participants were scheduled and invited to participate in an on-site survey to better understand the plant purchase choice decision-making. Each panelist was given a \$25 incentive for participating in the experiments. After being informed about the study purpose and signing an Institutional Review Board-approved informed consent form, subjects completed the demographic portion of the survey questionnaire. They were subsequently seated in front of the ET device (Tobii X1 Light, Danderyd, Sweden) and were oriented with and calibrated to the equipment (Behe et al., 2013a). The ET device allows researchers to track/ record eye movement across a computer screen. The ET device attaches to the bottom of the screen and refracts infrared beams of light off the eye pupil. The device captures the position on which the pupil is fixating or moving on the image/screen and records the sequence of gaze pattern at millisecond intervals. ET data are captured at the millisecond level, and as noted by Herpen and van Trijp (2011), differences in fixations at the second and millisecond level can provide meaningful results. For detailed information on time to calibrate and ET survey guidelines, see Behe et al. (2013a).

During orientation and calibration, participants were encouraged to sit as still as possible while viewing the displays on a computer screen. The visual data collection began with the subject viewing a sample display to become familiar with the study protocol. Next, participants were asked to verbally indicate how likely they were to purchase a plant within the display using a 10-point Likert willingness to purchase scale, where $1=$ not at all likely to buy and $10=$ very likely to buy. To reduce participant movement during the ET session, a researcher recorded the verbal response as a colleague advanced the screen to the next profile. To minimize order bias, the profile presentation was randomized between survey locations. Furthermore, the same laptop and computer screen were used at each location to ensure the image quality and size were the same between locations. After viewing the $16 \mathrm{im}$ ages, subjects completed supplemental questions with regard to their past plant purchases and other attitudinal and behavioral questions.

The images of plants were shown in 16-cm containers and were selected to represent transplants that were 1) food-producing; 2) edible; and 3) ornamental in nature. The plant type attribute was made up of three levels: mixed herbs, assorted vegetable plants, and petunias. The three price levels were: $\$ 1.99$, $\$ 2.49$, and $\$ 2.99 /$ plant. This range of prices was chosen after examination of prices at various garden centers in the cities used as venues for this research. Given the increasing popularity of environmental friendliness, understanding how consumers view environmental labeling is essential. We included three environmental production practice levels: "grown using water-saving practices," "grown using energy-saving practices," and "grown using sustainable practices," which were compared with the "grown using conventional practices" label. Information about consumers' valuation of attributes such as water-saving and energy-saving practices can benefit marketers to improve retail displays by messages that are relevant to end-users. From a production perspective, these practices have the potential to lower the need for water and energy, which are critical and often expensive inputs in plant production. However, if a producer is able to influence consumer demand for plants produced in a water- or energy-saving manner, then they can potentially increase their sales and/or receive a price premium.

The identification (ID) of the attributes and levels to be included in the survey are of critical importance. Using the results of previous studies, notably Behe et al. (2013b) and Hall et al. (2010), and consultations with retail garden center managers, we developed a conjoint experimental design consisting of a variety of intrinsic (plant types) and extrinsic (price and production practice) attributes. The combination of three attributes and corresponding levels represented a three $\times$ four $\times$ three design, i.e., three (plant types) $\times$ four (production practice levels) $\times$ three 3 (price levels) design. Given the number of attributes and levels, the total number of possible product profile combinations was 36 , which could result in cognitive burden and fatigue for the respondents. By using a fractional factorial design, the minimum number of stimuli was reduced to 16 plant profiles. Each plant profile shown to the participants consisted of a picture of a retail plant display, which was taken by the authors at a garden center in Dallas, TX, in Spring 2012. Using the display at the garden center and researchers' experience, a representative retail display was constructed that consisted of the desired plant type with three blank signs. After photographing the needed profiles, researchers used Adobe Photoshop to digitally add the prices and production practices onto the blank signs. The center sign always indicated the type of plants in the display (e.g., "assorted fresh herb plants," "annual petunias assorted colors," or "vegetable plants") given this is customary in most retail plant displays. The left sign always indicated the production practice, whereas the right sign always indicated the price per plant in the display. From each 
profile, the same pictures for herbs, petunias, and vegetables were used, ensuring no outside variation was introduced into the design. Furthermore, the sign text was the same font size and style across all signs and profiles.

After the ET experiments, Tobii Studio-3.0.2.218 (Tobii, Danderyd, Sweden) software was used to compile the visual metric calculations and specify areas of interest (AOIs). An AOI is a section of the image that the researcher chooses (by selecting a specific area of an image) to analyze in greater detail. For this study, four AOIs were created, one AOI for each sign and one for the plant display (not including the signs). The AOIs were drawn to fit each image closely (Fig. 1). To maintain consistency in AOI size and position among the 16 profiles, the AOI drawings were copied and pasted in place over each similar image in the test. After defining the AOIs for the profiles, the four metrics, time to first fixation (TFF), first fixation duration (FFD), total visit duration (TVD), and fixation count (FC) on each AOI, were calculated by the Tobii Studio Statistics tool.

The TFF is a measure of how many milliseconds it took a participant to first fixate on a particular AOI from the time the display (e.g., Fig. 1) appeared on the computer screen. A lower TFF implies the AOI commands attention. The FFD is the length of time in milliseconds that the participant fixated on an AOI during the first fixation. The TVD is the total time in milliseconds that the participant looked at a particular AOI. The FC is the number of times the participant fixated on an AOI.

Hypotheses. Consistent with Behe et al. (2013b) and Hall et al. (2010), we hypothesize $\left(\mathrm{H}_{1}\right)$ that the plant market is heterogeneous

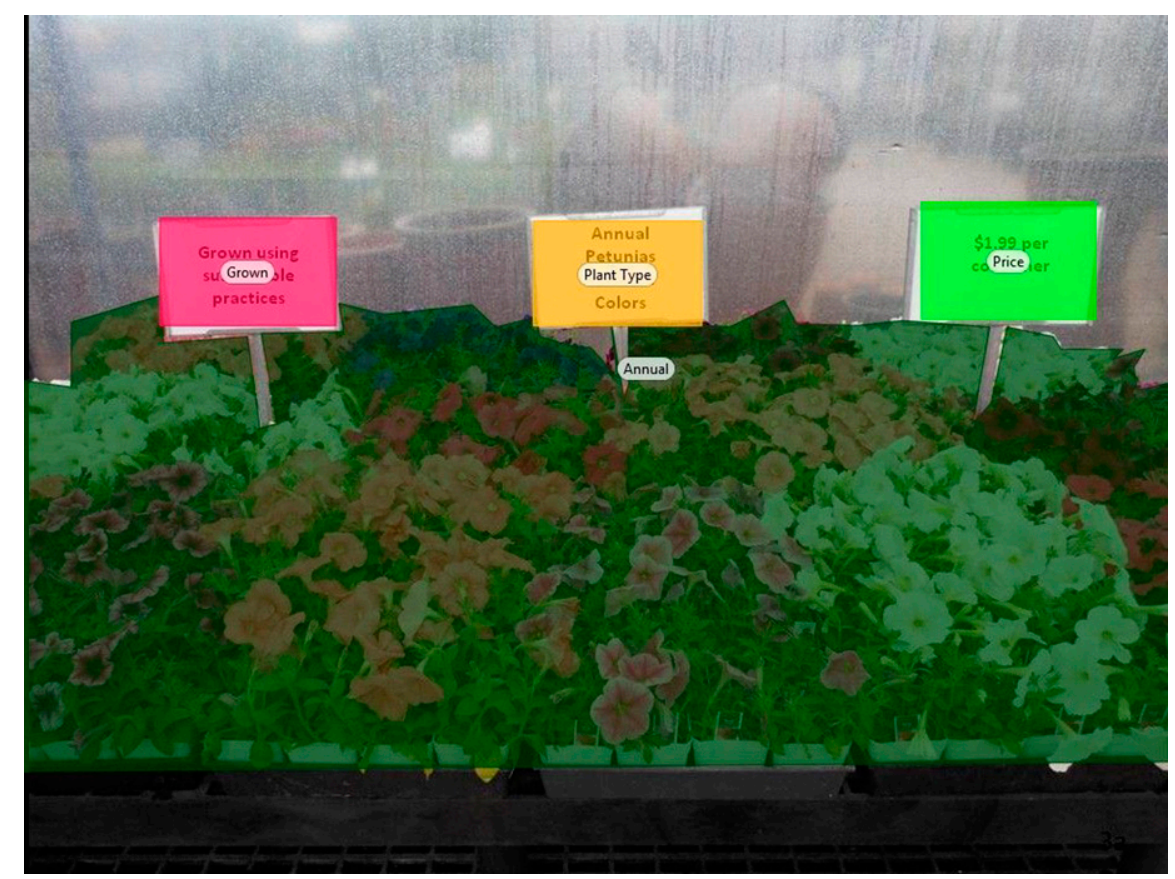

Fig. 1. Areas of interest imposed on a sample display used to compare respondent gaze. behavior when viewing plants and signage within the plant displays.

with distinct market segments. Furthermore, we hypothesize $\left(\mathrm{H}_{2}\right)$ that the cues that are more important to a consumer will be visually found before less important cues. For instance, a price-sensitive consumer will find the price sign faster than a consumer who is not pricesensitive $\left(\mathrm{TFF}_{\text {Price Sensitive }}<\mathrm{TFF}_{\text {Not Price Sensitive }}\right)$. We further hypothesize $\left(\mathrm{H}_{3}\right)$ that the cues that are more important to the consumer will also generate longer FFD, TVD, and a higher number of FCs compared with less important cues. Taking the price-sensitive consumer as an example, we expect that the price sign will see $\mathrm{FFD}_{\text {Price Sensitive }}>\mathrm{FFD}_{\text {Not Price Sensitive, }}$ $\mathrm{TVD}_{\text {Price Sensitive }}>\mathrm{TVD}_{\text {Not }}$ Price Sensitive, and $\mathrm{FC}_{\text {Price Sensitive }}>\mathrm{FC}_{\text {Not Price Sensitive }}$. In comparison across AOIs, we hypothesize $\left(\mathrm{H}_{4}\right)$ that the plant area AOI will have a faster TFF, TVD, FFD, and higher number of FCs across all consumer segments given it is larger than the other AOIs (typical in retail displays) and is arguably the most visually interesting (Fig. 1).

Lenzner et al. (2011) found that some study participants fixated longer when exposed to vague or imprecise terms, complex syntax, and low-frequency words or phrases. Because production method might contain unfamiliar or ambiguous terms (e.g., "sustainable," see Campbell et al., 2013), we hypothesized $\left(\mathrm{H}_{5}\right)$ that the production method sign would have the longest TFF, FFD, and TVD across signage.

Analyses. Numerous econometric modeling techniques such as probit, logit, and Tobit regressions have been used to analyze conjoint designs. However, given our desire to obtain individual-level estimates to obtain consumer segments, we used ordinary least squares (OLS) to construct individualized models for each participant. A part-worth

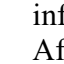
After the objective and subjective tests were
completed, three consumer segments ("plant-
oriented," "production practice oriented," and "price-oriented") were identified.

Using these segments, a multinomial logit model (ML) was used to identify any differences in demographics or purchasing behaviors that might increase the probability of being a member of a certain segment. The ML specification was as follows (Greene, 2003, p. 721):

$$
\operatorname{Prob}\left(S_{i}=j\right)=\frac{e^{\beta_{j}^{\prime} x_{i}}}{\sum_{k=1}^{3} e^{\beta_{k}^{\prime} x_{i}}} \quad \text { where } \mathrm{j}=1,2,3
$$

where $\operatorname{Prob}\left(\mathrm{S}_{\mathrm{i}}=\mathrm{j}\right)$ is the probability participant $i$ was in segment $j, k_{i}$ is a set of demographic and purchasing behavior variables, and $\beta_{\mathrm{j}}$ is a vector of parameters estimates. From the ML model, marginal effects were calculated at the means and are discussed in the "Results" section. Descriptive statistics for the explanatory variables can be found in Table 1. Along with identifying which demographics and purchasing 
Table 1. Means for the total sample and by segment from a 2012 study using eye tracking coupled with conjoint analysis associated with explanatory variables used in the multinomial logit model.

\begin{tabular}{|c|c|c|c|c|}
\hline & Total & Plant-oriented & Production method-oriented & Price-oriented \\
\hline \multicolumn{5}{|l|}{ State/province } \\
\hline Ontario & $19 \%$ & $20 \%$ & $21 \%$ & $15 \%$ \\
\hline Florida & $15 \%$ & $14 \%$ & $26 \%$ & $11 \%$ \\
\hline Texas & $18 \%$ & $19 \%$ & $9 \%$ & $20 \%$ \\
\hline Minnesota & $14 \%$ & $12 \%$ & $26 \%$ & $19 \%$ \\
\hline Michigan & $20 \%$ & $20 \%$ & $15 \%$ & $24 \%$ \\
\hline Indiana & $14 \%$ & $16 \%$ & $3 \%$ & $11 \%$ \\
\hline Age & 48.31 & 47.82 & 53.50 & 46.72 \\
\hline Gender: male & $29 \%$ & $31 \%$ & $21 \%$ & $24 \%$ \\
\hline Number of adults & 1.14 & 1.19 & 0.76 & 1.19 \\
\hline Number of children & 0.49 & 0.48 & 0.56 & 0.59 \\
\hline Ethnicity: white & $88 \%$ & $86 \%$ & $97 \%$ & $89 \%$ \\
\hline \multicolumn{5}{|l|}{ Education } \\
\hline High school degree or less & $11 \%$ & $13 \%$ & $6 \%$ & $6 \%$ \\
\hline 2-year college & $28 \%$ & $27 \%$ & $32 \%$ & $30 \%$ \\
\hline Bachelor's degree & $33 \%$ & $35 \%$ & $24 \%$ & $37 \%$ \\
\hline Higher than Bachelor's & $28 \%$ & $25 \%$ & $38 \%$ & $28 \%$ \\
\hline \multicolumn{5}{|l|}{ Area } \\
\hline Urban & $59 \%$ & $56 \%$ & $79 \%$ & $63 \%$ \\
\hline Metropolitan & $17 \%$ & $17 \%$ & $12 \%$ & $19 \%$ \\
\hline Rural & $24 \%$ & $27 \%$ & $9 \%$ & $19 \%$ \\
\hline Income & $\$ 70,650$ & $\$ 69,793$ & $\$ 72,685$ & $\$ 72,258$ \\
\hline Percent food budget spent on organic fresh produce & $20 \%$ & $21 \%$ & $24 \%$ & $15 \%$ \\
\hline Have a lawn $(1=$ no $)$ & $12 \%$ & $13 \%$ & $6 \%$ & $7 \%$ \\
\hline Dollars spent on garden supplies and plants, last 6 months & $\$ 338$ & $\$ 331$ & $\$ 381$ & $\$ 339$ \\
\hline Percent of plant purchases are locally produced & $56 \%$ & $55 \%$ & $60 \%$ & $61 \%$ \\
\hline \multicolumn{5}{|l|}{ Location of purchases } \\
\hline Independent garden center & $71 \%$ & $71 \%$ & $82 \%$ & $63 \%$ \\
\hline Home improvement or hardware store & $65 \%$ & $63 \%$ & $74 \%$ & $67 \%$ \\
\hline Supermarket or grocery store & $40 \%$ & $43 \%$ & $32 \%$ & $35 \%$ \\
\hline Mass merchandiser & $15 \%$ & $14 \%$ & $24 \%$ & $19 \%$ \\
\hline Other & $23 \%$ & $23 \%$ & $24 \%$ & $22 \%$ \\
\hline \multicolumn{5}{|l|}{ Plants purchased, last 6 months } \\
\hline Annual flowering & $69 \%$ & $70 \%$ & $74 \%$ & $65 \%$ \\
\hline Vegetable & $56 \%$ & $55 \%$ & $65 \%$ & $46 \%$ \\
\hline Herb & $50 \%$ & $49 \%$ & $56 \%$ & $48 \%$ \\
\hline Flowering perennials & $57 \%$ & $56 \%$ & $74 \%$ & $50 \%$ \\
\hline Shrub (flowering and non-flowering) & $34 \%$ & $33 \%$ & $47 \%$ & $26 \%$ \\
\hline Tree & $25 \%$ & $26 \%$ & $24 \%$ & $24 \%$ \\
\hline Indoor flowering potted & $42 \%$ & $42 \%$ & $56 \%$ & $33 \%$ \\
\hline
\end{tabular}

behaviors increase the probability of segment membership, we also used a multiple comparison test to determine if differences existed among TFF, FFD, TVD, and FC across each consumer segment for each sign (e.g., for price sign was $\mathrm{TFF}_{\text {Price-oriented }}<$ $\mathrm{TFF}_{\text {Plant-oriented). }}$.

\section{Results and Discussion}

The average $R^{2}$ across all individual OLS models was 0.76 , implying good fit for the models. For the conjoint analysis results, on average, respondents placed $50 \%$ of the relative importance (RI) on plant type, $27 \%$ on production methods, and $23 \%$ on price (Table 2). RI can be defined as the amount of importance an attribute contributes to the overall purchase decision (Hair et al., 1998). This was consistent with other findings where, on average, study participants ranked the RI of plant type highest (Behe et al., 2013b; Hall et al., 2010). We did find diversity in RI among the 330 participants, supporting $\mathrm{H}_{1}$ (The plant market is heterogeneous with distinct market segments.). Using the clustering procedure described previously to derive the market segments: $73 \%$ were categorized as plant-oriented, $11 \%$ as production method-oriented, and $16 \%$ were classified as price-oriented (Table 2). Members of the plant-oriented segment placed $7 \%$ more RI on plants compared with the sample in total. Members of the production methods segment placed $18 \%$ less RI on plant type, falling second to production method. For members of the price-oriented segment, RI of plant type dropped $20 \%$ to second place, whereas the RI of price increased $22 \%$ and ranked first.

In examining the part-worth utilities in Table 2, we observed that the moderately priced product $(\$ 2.49)$ was preferred over both lower and higher priced products, which is inconsistent with prior studies where lower prices were preferred. However, research has shown that consumers who are highly involved in a product category place less emphasis on the price cue than consumers who are less involved in the product category (Zaichkowsky, 1988). Involvement is considered "a state of arousal, interest or motivation" in a product (Rothschild, 1984). Furthermore, price can be an indicator of quality, and the $\$ 1.99$ price is one of the lowest prices found on the market, which might negatively influence preferences. The potential subtle relationship between price and quality perception should be examined in the future.
Plants showing "conventional" production practices signs were substantially discounted ( -0.21 ; Table 2$)$. The coefficients for the non-conventional production practice attributes ranged from 0.04 to 0.09 . The greatest increase in preferences was for water-saving production practices $(0.09)$, although it was not different from energy-saving (0.07). The positive preference for energy-saving practices was consistent with Behe et al. (2013b).

Part-worth utilities varied between consumer segments much like RIs did. Examining the production method-oriented segment first, the results showed that conventional production method was the least preferred $(-1.26)$, whereas substantial preference (on the magnitude of five to seven times larger) was placed on sustainable, water-saving, and energy-saving, which was more consistent with prior findings (Behe et al., 2013b). For the plant-oriented segment, we found that $57 \%$ of the purchase decision was based on plant type with little to no influence by production practice. The price-oriented segment preferred the middle price (\$2.49) with only small preference for the "environmentally friendly" production practices.

Using the marginal effects, we found that the three segments differed on a few demographic 
Table 2. Mean relative importance and part-worth utility values for the total sample and by consumer segment.

\begin{tabular}{|c|c|c|c|c|}
\hline & Total & Plant- oriented & Production method-oriented ${ }^{\mathrm{z}}$ & Price-oriented ${ }^{z}$ \\
\hline Number & 330 & 242 & 34 & 54 \\
\hline Market share & & $73 \%$ & $11 \%$ & $16 \%$ \\
\hline \multicolumn{5}{|c|}{ Relative importance (mean) } \\
\hline Price & $23 \%$ & $19 \%$ & $15 \%$ & $45 \% * * *$ \\
\hline Production & $27 \%$ & $24 \%$ & $53 \% * * *$ & $24 \%$ \\
\hline Plant type & $50 \%$ & $57 \%$ & $32 \% * * *$ & $30 \% * * *$ \\
\hline \multicolumn{5}{|c|}{ Part-worth utilities (mean) } \\
\hline Intercept & 6.61 & 6.54 & 6.93 & 6.71 \\
\hline \multicolumn{5}{|l|}{ Price $(\$)$} \\
\hline 1.99 & -0.12 & -0.15 & $0.10 * * *$ & -0.16 \\
\hline 2.49 & 0.30 & 0.17 & 0.17 & $1.00 * * *$ \\
\hline 2.99 & -0.18 & -0.02 & $-0.26 * * *$ & $-0.84 * * *$ \\
\hline \multicolumn{5}{|l|}{ Production label } \\
\hline Conventional & -0.21 & -0.06 & $-1.26 * * *$ & $-0.22 * *$ \\
\hline Sustainable & 0.04 & 0.00 & $0.29 * * *$ & 0.07 \\
\hline Energy-saving & 0.07 & 0.01 & $0.52 * * *$ & 0.06 \\
\hline Water-saving & 0.09 & 0.04 & $0.45 * * *$ & 0.09 \\
\hline \multicolumn{5}{|l|}{ Plant type } \\
\hline Herb & 0.05 & 0.04 & 0.38 & -0.04 \\
\hline Vegetable & -0.10 & -0.13 & -0.24 & 0.08 \\
\hline Annual & 0.05 & 0.09 & -0.14 & -0.04 \\
\hline$R^{2}$ & 0.76 & 0.77 & 0.78 & 0.73 \\
\hline Adjusted $R^{2}$ & 0.73 & 0.74 & 0.75 & 0.69 \\
\hline
\end{tabular}

${ }^{\mathrm{z}} t$ tests were used to compare the relative importance and part-worth utilities associated with the production and price segments to the main (total) segment.

$*, * *$, and ${ }^{* * *}$ represent significant differences at the $0.1,0.05$, and 0.01 levels, respectively.

and behavioral parameters (Table 3). Geographically, the only statistically significant marginal effect was found for the indicator variable for Indiana. In other words, production method-oriented consumers were slightly less likely to have been from Indiana compared with those consumers from Ontario. Each additional adult in the household (above the average number of adults) increases the probability of being in the plant-oriented segment by $5.1 \%$ and decreases the probability of being in the production method segment by $4.4 \%$. Plant-oriented consumers were $9 \%$ more likely to live in rural areas, whereas production method-oriented consumers were $3 \%$ less likely to live in a rural area compared with an urban area. Price-oriented consumers were slightly less likely to have spent a higher percentage of their food budget on organic products. Not surprisingly, plant-oriented consumers were $8 \%$ more likely to have a lawn but slightly less likely to have purchased a higher percentage of local plants. Price-oriented consumers were slightly more likely to have bought a higher percentage of their plants locally. Production method-oriented consumers were slightly more likely to have spent a higher amount on garden supplies and plants in the 6 months before the study. Consumers in this segment were also slightly more likely to have purchased plants from a mass merchandiser.

Visual data analysis. TFF is a metric indicating the amount of time an element (i.e., an AOI) took to capture attention, so lower times indicate an element that commanded attention quickly. Because the plant ID sign was centrally located on every image, we anticipate it to have the shortest TFF, consistent with central gaze theory (Atalay et al.,
2012; Christenfeld, 1995; Shaw et al., 2000). However, only the plant-oriented consumer segment had the lowest TFF for the plant ID sign compared with the other signs (Table $4)$. For instance, it took the plant-oriented segment $1.15 \mathrm{~s}$ to fixate on the plant ID sign while taking 1.23 and $1.89 \mathrm{~s}$ to fixate on the production and price signs, respectively. However, the production-oriented segment took $1.27 \mathrm{~s}$ to fixate on the plant ID sign and 0.90 and $2.01 \mathrm{~s}$ to fixate on the production and price signs, respectively. There may be two plausible explanations for this result. First, people tend to read/look left to right implying that because the production sign was on the left, then it was fixated on faster. However, if this were the case, then we would expect the plant-oriented segment to have a lower TFF for the plant ID sign, which does not occur. More likely the reason for the production and price-oriented segments fixating on the production sign fastest is the result of the sign containing unfamiliar, irrelevant, or confusing information, consistent with Lenzner et al. (2011). In other words, the plant-oriented segment was most likely fixating on the plants to come up with valuations, whereas the production and price-oriented consumers were making valuations based on production and price.

With respect to TFF differences associated with specific signs/plants across segments $\left(\mathrm{H}_{2}\right.$ : the cues that are more important to a consumer will be visually found before less important cues), the results showed that the plant ID sign had a shorter TFF for the plant-oriented group $(1.15 \mathrm{~s})$ compared with the other groups (production-oriented $=1.27$ and price-oriented $=1.35$ ), supporting $\mathrm{H}_{2}$. Furthermore, the plant-oriented segment had a lower $\operatorname{TFF}(0.79)$ for the plant material compared with the production (1.21) and price (1.62) -oriented segments. For the production sign, the production-oriented consumers had a lower TFF compared with the plant-oriented consumers. Finally, the price-oriented segment had a lower TFF for the price sign compared with the other segments. These results fully support $\mathrm{H}_{2}$ that consumers with varying drivers of purchase will first fixate on those aspects of the sign/product of interest to them.

FFD is an indication of the time used to process information from the first fixation (Table 5). The plant-oriented segment had the longest FFD on the plants compared with the other two segments, 0.04 and $0.02 \mathrm{~s}$, more than that of production and price-oriented consumers. This finding supports $\mathrm{H}_{3}$. (Cues that are more important to the consumer will also generate longer FFD, TVD, and a higher number of FCs compared with less important cues.) However, all three segments spent the lowest FFD on the plants, which does not support $\mathrm{H}_{4}$. (The plant area AOI will have a faster TFF, TVD, FFD, and higher number of FCs across all consumer segments.) The price sign had the third longest FFD for all three groups and was equally long across them. The FFD for the production sign was longest for all three groups. However, for the price-oriented group, FFD was 2 ms shorter than for the production method-oriented segment and $1 \mathrm{~ms}$ shorter than for the plant-oriented segment. Thus, $\mathrm{H}_{3}$ was partially supported in that FFD on price was shorter than FFD on production method sign, but FFD on plants was not shorter than FFD on the plant ID sign.

TVD is an indirect measure of cognitive processing in that it is a product of FC multiplied by fixation duration per visit. Table 6 shows the TVD for each of the four AOIs by segment. When comparing the TVD on each of the three signs, the results showed that the TVD on the central sign (plant ID) was lower than the production method sign for all three segments, supporting $\mathrm{H}_{4}$. Members of all three segments had the highest TVD on the plants, also supporting $\mathrm{H}_{4}$. However, in comparing the mean TVD by segment, the plant-oriented segment had a longer TVD on the plants compared with the other two segments. The production method-oriented segment had a longer mean TVD on the production method sign compared with the other two groups. The results also revealed that the price-oriented consumers had a longer TVD on the price sign compared with the other segments.

Furthermore, the results showed that the production sign does have the highest TVD across all signage for each market segment. From these results for TVD, we find that $\mathrm{H}_{3}$ (cues that are more important to the consumer will also generate longer FFD, TVD, and a higher number of FCs compared with less important cues) and $\mathrm{H}_{5}$ (the production method sign would have the longest TFF, FFD, and TVD across signage) are supported. Our findings support $\mathrm{H}_{3}$ (cues that are more important to the consumer will also generate longer FFD, TVD, and a higher number of 
Table 3. Marginal effects calculated at the means (representing the likelihood of inclusion in each segment for each independent variable) for each segment from the multinomial logit model.

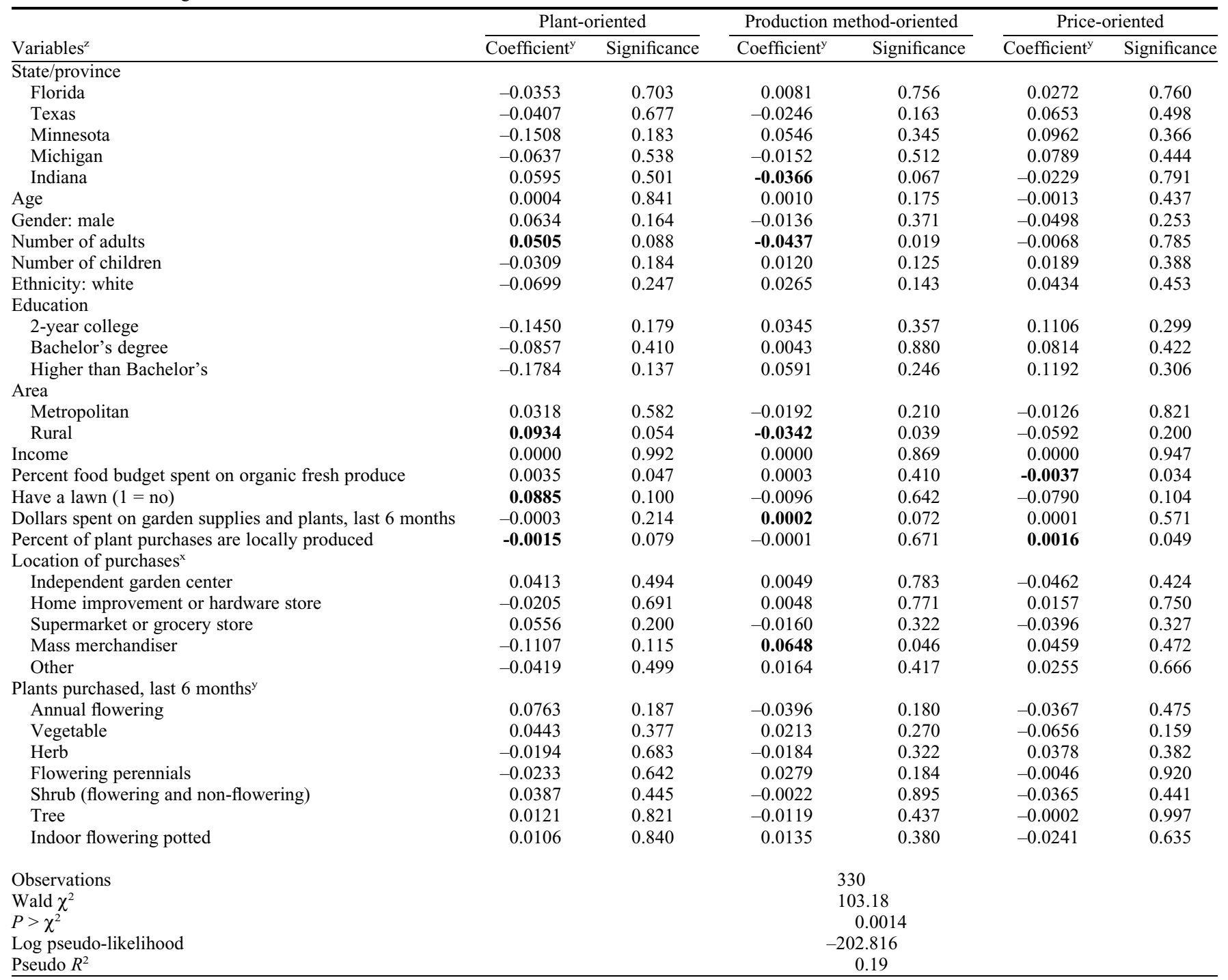

${ }^{\mathrm{z}}$ Base categories include: Ontario, female, other ethnic heritage, high school diploma or less, urban, and have a lawn.

${ }^{y}$ Bold values indicate significant differences at the 0.1 level; see $P$ value for the exact level.

${ }^{\mathrm{x}}$ For the location of purchase (and plants purchased) variables, the respondent could mark any of the stores (or plant types), so the base category is did not purchase from (did not purchase this type of plant).

$*, * *$, and $* * *$ represent significant differences at the $0.1,0.05$, and 0.01 levels, respectively.

Table 4. Time to first fixation (in seconds) by segment during the eye tracking portion of the study. ${ }^{\mathrm{z}}$

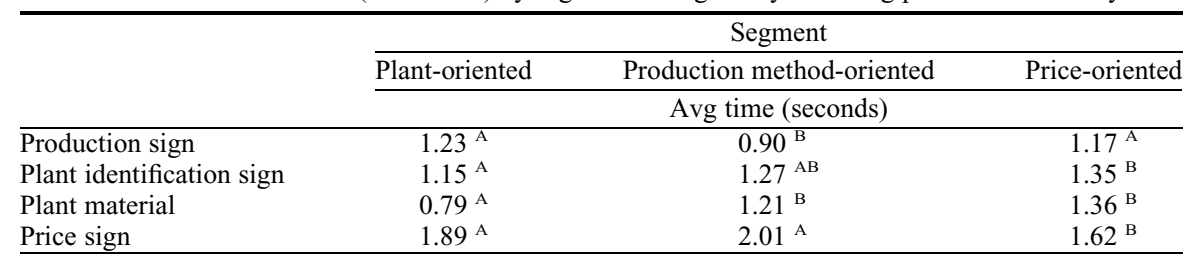

${ }^{\mathrm{z}} \mathrm{A}$ Bonferroni multiple comparison test was used to test for differences between the different segments. For example, a superscript B in the "Plant-oriented" segment for the production sign indicates that 0.90 is significantly different at the 0.1 level or less compared with the "Plant-oriented" and "Price-oriented" segments.

FCs compared with less important cues), that consumers look at the cues that they value, it is more important than ever for green industry firms to be aware of the effects of signage they use in their display. Furthermore, because our results also support $\mathrm{H}_{5}$ (production signage has a higher TVD com- pared with other signs), firms should be aware that production-method signs will take away viewing time from other signage regardless of whether the consumer values the production practice. Thereby, retailers wanting to focus less on production should use clear and concise terminology so that consumers will fixate less on the production practice and more on other signage (or product) that the firm wants to emphasize.

\section{Conclusions}

Markets are not homogeneous, and it is not surprising that the consumers are heterogeneous in their preferences and the relative importance they place on different product cues. This study is one of the first efforts to document the relationship between the stated preference for products in a retail display and visual data collected with ET. There are many cues available in the shopping environment, including signs and the merchandise itself, which the consumer could use to make a purchase decision. Our results showed that plant-oriented consumers used the intrinsic cue (the plant itself) over other extrinsic cues (signs), consistent with 
Table 5. First fixation duration (in seconds) and percent of total visual time spent on first fixation by segment during the eye tracking portion of the study. ${ }^{z}$

\begin{tabular}{|c|c|c|c|c|c|c|}
\hline & \multicolumn{6}{|c|}{ Segment } \\
\hline & \multicolumn{2}{|c|}{ Plant-oriented } & \multicolumn{2}{|c|}{ Production method-oriented } & \multicolumn{2}{|c|}{ Price-oriented } \\
\hline & $\begin{array}{l}\text { Avg time } \\
\text { (seconds) }\end{array}$ & $\begin{array}{l}\text { Percent time for } \\
\text { first fixation }\end{array}$ & $\begin{array}{l}\text { Avg time } \\
\text { (seconds) }\end{array}$ & $\begin{array}{l}\text { Percent time for } \\
\text { first fixation }\end{array}$ & $\begin{array}{l}\text { Avg time } \\
\text { (seconds) }\end{array}$ & $\begin{array}{l}\text { Percent time for } \\
\text { first fixation }\end{array}$ \\
\hline Production sign & $0.40^{\mathrm{A}}$ & $59 \%$ & $0.39^{\mathrm{AB}}$ & $34 \%$ & $0.37^{\mathrm{B}}$ & $38 \%$ \\
\hline $\begin{array}{l}\text { Plant identification } \\
\text { sign }\end{array}$ & $0.26^{\mathrm{A}}$ & $49 \%$ & $0.25^{\mathrm{A}}$ & $38 \%$ & $0.25^{\mathrm{A}}$ & $38 \%$ \\
\hline Plants & $0.22^{\mathrm{A}}$ & $9 \%$ & $0.18^{\text {в }}$ & $9 \%$ & $0.20^{\mathrm{C}}$ & $11 \%$ \\
\hline Price sign & $0.34^{\mathrm{A}}$ & $79 \%$ & $0.32^{\mathrm{A}}$ & $51 \%$ & $0.33^{\mathrm{A}}$ & $37 \%$ \\
\hline
\end{tabular}

${ }^{\mathrm{z}} \mathrm{A}$ Bonferroni multiple comparison test was used to test for differences between the different segments. For example, a superscript AB in the "Plant-oriented" segment for the production sign indicates that 0.39 is not significantly different at the 0.1 level or less compared with the "Plant-oriented" and "Priceoriented" segments.

yercent of time for first fixation indicated the proportion of total time on the image that was accounted for by the first fixation.

Table 6. Total visit duration (in seconds) by segment during the eye tracking portion of the study. ${ }^{2}$

\begin{tabular}{lccc}
\hline & \multicolumn{3}{c}{ Segment } \\
\cline { 2 - 4 } & Plant-oriented & Production method-oriented & Price-oriented \\
\cline { 2 - 4 } & & (seconds) & $0.97^{\mathrm{C}}$ \\
Production sign & $0.68^{\mathrm{A}}$ & $1.16^{\mathrm{B}}$ & $0.66^{\mathrm{B}}$ \\
Plant identification sign & $0.53^{\mathrm{A}}$ & $0.67^{\mathrm{B}}$ & $1.77^{\mathrm{C}}$ \\
Plants & $2.36^{\mathrm{A}}$ & $2.11^{\mathrm{B}}$ & $0.89^{\mathrm{C}}$ \\
Price sign & $0.43^{\mathrm{A}}$ & $0.63^{\mathrm{B}}$ & \\
\hline
\end{tabular}

${ }^{\mathrm{z}} \mathrm{A}$ Bonferroni multiple comparison test was used to test for differences between the different segments. For example, a superscript B in the "Plant-oriented" segment for the production sign indicates that 0.68 is significantly different at the 0.1 level or less compared with the "Production method-oriented" (1.16) and "Price-oriented" (0.97) segments.

Olson's (1972) two-step cue assessment theory in which consumers first identify important cues before using them in judgments. Overall, our data revealed congruency between cue preference and attention measures. For example, the plant-oriented segment fixed their gaze most quickly (TFF) on the preferred intrinsic cue (plant itself), whereas the production-oriented segment's TFF was fastest for the production sign. Understanding consumer cue preferences can assist retailers in providing display cues that grab consumer attention.

Decades of consumer research has documented the persistent impact that price has on product perceptions. Price is a relatively common and simple message to convey. In this study we found that the price-oriented consumers had a longer TVD on the price sign compared with the other segments. This indicates they were thinking about price longer than individuals in other segments and longer than other extrinsic cues (i.e., production and plant ID sign). Given consumers' tendency to choose an option in the center, the first fixation for our participants would be expected to be on the plant ID sign. For production methodoriented consumers, TFF was lowest on the production sign, not on the plants or the central ID sign. This cue (i.e., production sign) was high in RI in their stated cue preference as well as commanding their visual attention. Our results are comparable with previous empirical work (Meissner and Decker, 2010) in that consumers spend more time fixating on the cues that are important to them.

This study provides some of the first objective visual data, which relates stated preference to eye movement. Our experiments showed that consumers identified and considered information consistent with their stated preference, supporting Olson's (1972) theory. Findings suggest that retailers should carefully consider information included on signs and the relative importance those terms may have to a variety of consumers. A fruitful area for future study will be to investigate the relationship between relative importance of product cues and measures of attention to actual purchase behavior. This line of research is made feasible with the use of ET glasses at the point of purchase. Although ET can provide insights into what grabs consumer attention, these data need to be combined with other measures (e.g., product involvement, price sensitivity) to better understand why certain product cues are relevant.

We also find through ETT that not only does each consumer segment find the most important cue faster than the other segments, but they look at it longer. In a maturing green industry marketplace, this result can be extremely useful because retail firms need to not only catch attention, but showcase relevant information to increase the probability of each consumer purchase. A green industry firm can use the consumer profiles from our study to stress certain marketing messages with the knowledge that consumers do indeed look for them.

\section{Literature Cited}

Allison, R.I. and K.P. Uhl. 1964. Influence of beer brand identification on taste perception. J. Mktg. Res. 1:36-39.
Atalay, A.S., H.O. Bodur, and D. Raslofoarison. 2012. Shining in the center: Central gaze cascade effect on product choice. J. Consum. Res. 39:848-866.

Behe, B. and S. Barton. 2000. Consumer perceptions of product and service quality attributes in six U.S. states. J. Environ. Hort. 18:71-78.

Behe, B., J. Hardy, S. Barton, J. Brooker, T. Fernandez, C. Hall, J. Hicks, R. Hinson, P. Knight, R. McNiel, T. Page, B. Rowe, C. Safley, and R. Schutzki. 2005a. Landscape plant material, size, and design sophistication increase perceived home value. J. Environ. Hort. 23:127-133.

Behe, B.K., R.M. Walden, M. Duck, B. Cregg, K. Kelley, and R.D. Lineberger. 2005b. Consumer preferences for and cost of production of tabletop Christmas trees. HortScience 40: 409-412.

Behe, B.K., R.T. Fernandez, P.T. Huddleston, S. Minahan, K.L. Getter, L. Sage, and A.M. Jones. 2013a. Practical field use of eye tracking for consumer research in the retail environment. HortTechnology 23:517-524.

Behe, B.K., B.L. Campbell, C.R. Hall, H. Khachatryan, J.H. Dennis, and C. Yue. 2013b. Consumer preferences for local and sustainable plant production characteristics. HortScience 48: 209-215.

Bix, L., N.M. Bello, R. Auras, J. Ranger, and M.K. Lapinski. 2009. Examining the conspicuousness and prominence of two required warnings on OTC pain relievers. Proc. Natl. Acad. Sci. USA 106:6550-6555.

Caliìnski, T. and J. Harabasz. 1974. A dendrite method for cluster analysis. Commun. Stat. $3: 1-27$.

Campbell, B.L., H. Khachatryan, J. Dennis, C. Hall, and B.K. Behe. 2013. . Consumer perceptions and misperceptions of ecofriendly and sustainable terms. Agr. Res. Econ. Rev. (in press).

Carson, R.T. and J.J. Louviere. 2011. A common nomenclature for stated preference approaches. Environ. Resour. Econ. 49:539-559.

Christenfeld, N. 1995. Choices from identical options. Psychol. Sci. 6:50-55.

Dodds, W.B., K.B. Monroe, and D. Grewal. 1991. Effects of price, brand, and store information on buyers' perceptions of product quality and value. J. Mktg. Res. 28:307-319.

Duda, R.O., P.E. Hart, and D.B. Stork. 2001. Pattern classification and scene analysis. 2nd Ed. Wiley, New York, NY.

Gabor, A. and C.W. Granger. 1961. On the price consciousness of consumers. Appl. Stat. 10:170-188

Green, P.E. and K. Helsen. 1989. Cross-validation assessment of alternatives to individual-level conjoint analysis: A case study. J. Mktg. Res. 26:346-350.

Greene, W.H. 2003. Econometric analysis. 5th Ed. Prentice Hall, Upper Saddle River, NJ.

Hair, J.F., Jr., R.E. Anderson, R.L. Tatham, and W.C. Black. 1998. Multivariate analysis. 5th Ed. Prentice Hall, Upper Saddle River, NJ.

Hall, C., B. Campbell, B. Behe, C. Yue, J. Dennis, and R. Lopez. 2010. The appeal of biodegradable packaging to floral consumers. HortScience 45:583-591.

Herpen, E. and H.C.M. van Trijp. 2011. Front-ofpack nutrition labels. Their effect on attention and choices when consumers have varying goals and time constraints. Appetite 57:148-160.

Hudson, J., B.K. Behe, H.G. Ponder, and W.E. Barrick. 1997. Consumer perceptions and expectations of garden center product and service quality. J. Environ. Hort. 15:12-15. 
Janakiraman, N., R.J. Meyer, and A.C. Morales. 2006. Spillover effects: How consumers respond to unexpected changes in prices and quality. J. Consum. Res. 33:361-372.

Klingeman, W.E., D.B. Eastwood, J.R. Brooker, C.R. Hall, B.K. Behe, and P.R. Knight. 2004 Consumer survey identifies plant management awareness and added value of dogwood powdery mildew resistance. HortTechnology 14:275-282.

Kotler, P. and G. Armstrong. 2001. Principles of marketing. 9th Ed. Prentice Hall, Upper Saddle River, NJ.

Koutsimanis, G., K. Getter, B. Behe, J. Harte, and E. Almenar. 2012. Influences of packaging attributes on consumer purchase decisions for fresh produce. Appetite 59:270-280.

Kuisma, J., J. Simola, L. Uusitalo, and A. Oorni. 2010. The effects of animation and format on the perception and memory of online advertising. J. Interactive Mktg. 24:269-282.

Lenzner, T., L. Kaczmirek, and M. Galesic. 2011. Seeing through the eyes of the respondent: An eye-tracking study on survey question comprehension. J. Public Opinion Res. 23:361-373.

Mason, S., T. Starman, R.D. Lineberger, and B.K. Behe. 2008. Consumer preferences for price, color harmony and care information of container gardens. HortScience 43:380-384.
McDaniel, C. and R.C. Baker. 1977. Convenience food packaging and the perception of product quality. J. Mktg. 41:57-58.

Meissner, M. and R. Decker. 2010. Eye tracking information processing in choice-based conjoint analysis. Intl. J. Mkt. Res. 52:591-610.

Olson, J. 1978. Inferential belief formation in the cue utilization process, p. 35-43. In: Hunt, H. (ed.). Advances in consumer research. Vol. 5. Association for Consumer Research, Ann Arbor, MI.

Olson, J.C. 1972. Cue utilization in the quality perception process: A cognitive model and an empirical test. doctoral dissertation, Purdue University, West Lafayette, IN.

Patalano, A.L., B.J. Juhasz, and J. Dicke. 2009. The relationship between indecisiveness and eye movement patterns in a decision making informational search task. J. Behav. Decis. Making 23:353-368.

Rao, A.R. 2005. The quality of price as a quality cue. J. Mktg. Res. 42:401-405.

Rayner, K. 1998. Eye movements in reading and information processing: 20 years of research Psychol. Bull. 124:372-422.

Richardson, P.S., A.S. Dick, and A.K. Jain. 1994. Extrinsic and intrinsic cue effects on perceptions of store brand quality. J. Mktg. 58:28-36.

Rothschild, T.S. 1984. Perspectives on involvement: Current problems and future directions.
In: Kinnear, T. (ed.). Advances in consumer research. Vol. 11. Association for Consumer Research, Ann Arbor, MI.

Shaw, J.I., J.E. Bergen, C.A. Brown, and M.E. Gallagher. 2000. Centrality preferences in choices among similar options. J. Gen. Psychol. 127:157-164.

Sorensen, H.S., J. Clement, and G. Gabrielsen. 2012. Food labels - An exploratory study into label information and what consumers see and understand. Intl. Rev. Retail Distrib. Consum. Res. 22:101-114.

Teixeira, T.S., M. Wedel, and R. Pieters. 2010. Moment-to-moment optimal branding in TV commercials: Preventing avoidance by pulsing. Mktg. Sci. 29:783-804

Vanhuele, M., G. Laurent, and X. Dreze. 2006. Consumers' immediate memory for pricesJ. Consumer Res. 33:163-174.

Wedel, M. and R. Pieters. 2008. Eye tracking for visual marketing. Foundations and Trends in Mktg. 1:231-320.

Zagaden, Y., B.K. Behe, and R. Gough. 2008. Consumer preferences for native plants in Montana residential landscapes and perceptions for naturalistic designs. J. Environ. Hort. 26:109-114.

Zaichkowsky, J.L. 1988. Involvement and the price cue. Adv. Consum. Res. 15:323-327. 